\title{
A Comparative Study of Apologetic E-mails Used by Males and Females Iranian EFL Learners Compared to English Native Speaking Students
}

\author{
Zeinab Mohamadi \\ University of Isfahan, Isfahan, Iran
}

\begin{abstract}
The purpose of this study was to compare apology strategies used by Iranian EFL learner students and native English speaking students (NSS) in formal and informal situations. The aim was further to investigate gender differentiation among participants. For this purpose, data were elicited from 40 Iranian (16 males and 24 females) and 40 native English speaking students (20 males and 20 females) through a Discourse completion task questionnaire. The findings of the study revealed specific similarities and differences in terms of frequency and percentage for apologetic strategies used by Iranian and native English speaking students. These findings could be a pedagogical help to teachers, students and those interested in interlanguage pragmatics.
\end{abstract}

Index Terms —apology, apology strategies, Iranian EFL learners, native English speaking students, gender

\section{INTRODUCTION}

As it is well known, using e-mail is now a widely and frequently used interpersonal communication medium. In fact, it is becoming an accepted means of communication between university students and their professors. But it might be the case that students are not certain about email writing due to lack of experience. E-mails, if used appropriately, can create a new channel for student-instructor and friend-friend communication particularly in academic settings.

This paper tries to focus on the apology speech act in a specific type of e-mail that is used by students to make apology to their professors and also to their friends in academic setting. As we know, making apology to professors and also to friends through e-mails has become a common discourse practice for students. For example they often use emails to apology for being late in doing some assignment or not fully understanding some points and etc. and also it is somehow common among students to their friends. However since in professor - students' relationship, professors are in higher status and in friend - friend relationship, friends have the same status, the way the students perceive the power relation is so important. It makes students to use different strategies for communicating with professors and different strategies for communicating with their friends.

For non-native students, there are factors that will affect their choice of discourse strategies in making apology to professors and to friends in e-mail. One important factor is distance and social relation. It will likely affect their use of apology strategies in terms of being polite or being intimate (Chalak, 2009).

As it has been observed, Iranian EFL learners are likely to write their email apology to their professors and to their friends variously from those of English native speakers. This study was an investigation into Iranian English foreign language learners and English native speaking students in sending e-mails to their professors and to their friends. So, this paper compared the discourse strategies used in such apologetic e-mails by Iranian EFL learners and English native speaking students.

Also, it is known that gender differences have an influence on the selection of formulas for the realization of apology. To what extent are apologetic strategies different and are there any similarities among students in different genders? This study also investigated how native and non-native males and females apologize in dealing with their instructors and friends.

\section{REVIEW OF LITERATURE}

Over the past years, using e-mail for communication has increased surprisingly, in almost all social settings; at works, between friends, and in academic settings. Particularly using e-mails at universities and colleges has been more common. It assumes a number of functions such as the delivery of assignment, or about the procedures of the course (Poling 1994; Shetzer, 1998; Worrel, 2002).

In most universities, communication via e-mail has become one of the most frequently used means for students to consult with their professors (Abdullah, 1998; Kirkley, Savery, \& Grabner-Hagen, 1998). 
Research on e-mail use in academic setting has mostly focused on e-mails that are exchanged between nonnative speakers of English and native speakers (Biesenbach-Lucas, 2005, 2006, 2007; Li, 2000; Chen, 2001, 2006).

Rod \& Eslami-Rasekh (2005) have studied openings in e-mail discourse of native and nonnative TESOL graduate students. Eslami-Rasekh \& Eslami Rasekh (2007) have studied openings and closings in e-mail discourse of Iranian NNES and NES TESOL graduate students.

Research on apology has been started from the work of Goffman (1971). It has been continued by Holmes (1990) and Robinson (2004). Also, studies in this relation both in native and non-native languages (Eslami, 2004; Shariati and Chamani, 2010) have been conducted to address the strategies that used for conveying the illocutionary act and contextual features that influence on the choice of these strategies.

Apology has been studied extensively in previous pragmatic studies in different languages in comparison with English: Cantonese (Rose, 2000), Danish (Trosborg, 1995), Hungarian and Italian (Bardovi-Harlig \& Dornyei, 1998), Hebrew (Olshtain, 1989; Olshtain \& Blum-Kulka, 1985), Japanese (Kondo, 1997; Maeshiba, Yoshinaga, Kasper, \& Ross, 1996) and Korean (Kim, 2001; Lee, 2000) Such studies in apology have produced some main findings. Apology research, both in western and eastern languages (Eslami, 2004; Shariati and Chamani, 2010), has primarily addressed the strategies used to convey the illocutionary act and the contextual factors that influence the choice of these strategies.

Holmes (1993) and Mohammad Dadkhah Tehrani (2012) studied gender differences in apologies and found both similarities and differences between males and females. She found that women apologize significantly more than men and also they apologize most to hearers of equal power while men apologize to women irrespective of status.

Cohen and Olshtain (Cohen and Olshtain, 1985; Olshtain and Cohen, 1983) developed a questionnaire consisting of eight situations, five varying in terms of status and solidarity relations between the participants, and the remaining three holding status and solidarity constant, but varying in severity of the offense. The same questionnaire has been employed in some later studies, such as Ang-Abey, 1991 (Hokkien Chinese of Sarawak Malaysia), Suszczynska, 1994 (American English and Hungarian), Suszczynska, 1999 (American English, Polish, and Hungarian), and Eslami-Rasekh, 2004 (American English and Persian). The CCSARP (Cross-Cultural Study of Speech Act Realization Patterns) project made use of a set of seven situations (two of which are also found in Olshtain and Cohen's work), with variation in status and solidarity relations, but not in severity of offense, to investigate a variety of languages, including Hebrew, Canadian French, Australian English, and German (Olshtain, 1989). A number of other scholars have done similar works, using written or spoken discourse completion tests, but using situations of their own devising, usually with variation in status and solidarity relations and/or severity of offense, for example Bergman and Kasper 1993 (Thai), Meier 1996, 1997 (Austrian German), Bataineh 2004 (Jordanian Arabic), Lee 2000 (Korean) and Okumura and Wei 2000 (Japanese).

In addition to differences in method of data collection, there is remarkable variation in the categories of analysis used from one study to another. Cohen and Olshtain (Cohen and Olshtain, 1981; Olshtain and Cohen, 1983) proposed a speech-act set for apologizing which consisted of five semantic formulas: an expression of apology, taking on responsibility, explanation or account, offer of repair and promise of forbearance.

Wouk (2006) stated that, in the analysis of their results, all these studies made reference to Cohen and Olshtain's speech act set, but in a number of cases, additional strategies were included. He stated that it would seem, in spite of the large amount of work that has been done on the practice of apologizing, many issues relating to the choice of strategies remain unresolved.

According to the studies of Woulk (2006) different scholars define apology in different ways. It has been defined as a remedial action (Goffman, 1971), and as an act of verbal redress, used when social norms have been violated by a real or potential offense (Olshtain, 1989). Investigation of apologies began in the early 1980s. Owen (1983) looked at apologies from a Goffmanian perspective, as a type of ritual action, specifically a type of remedial interchange. However, the impetus for most later studies on apologizing was provided by the work of Olshtain and Cohen (Cohen and Olshtain, 1981; Olshtain and Cohen, 1983), in developing Fraser's (1981) notion of a 'speech-act set' of strategies for apologies, and its further development by Blum-Kulka and Olshtain (1984) in conjunction with the CCSARP (Cross-Cultural Study of Speech Act Realization Patterns) project.

Bergman and Kasper (1993) defined an apology as "a compensatory action to an offense in the doing of which speaker was casually involved and which is costly to hearer". Brown and Levinson (1987) claimed that all speakers choose the same strategies under the same conditions, and tried to demonstrate this by looking at three different languages, namely English, Tzeltal (a Mayan language), and South Indian Tamil.

One of the most influential views about the classification of apologies is Goffman's (1971). He distinguishes two types of compensations: ritual and substantive' (Nureddeen, 2008: 282). Following this distinction, Fraser (1981, 265) provides two motivations associated with substantive and ritualistic apologies; in substantive apology the speaker wants to remedy the damage or harm caused by the offense while the ritual apology may be produced as a kind of habit associated with certain routines.

Fraser (1981) and Nureddeen (2008) provide an extended list of strategies which includes announcing apology, stating obligation to apologize, offering to apologize, requesting hearer to accept the apology, expressing regret, requesting forgiveness, acknowledging responsibility, promising forbearance, and offering redress. 
Olshtain and Cohen (1983:22-23) and Nureddeen (2008) state that apologies are realized by one of these five strategies: an illocutionary force indicating device (IFID), an expression of responsibility for the offence, an account of cause of violation, an offer of repair, and a promise of forbearance.

Another classification for apology was proposed by Blum Kulka and Olshtain (1984: 206) who provided five verbs (regret, excuse, be sorry, forgive, pardon) beside (apologize) which they considered as performative verbs in English.

Blum-Kulka and Olshtain 1984; Trosberg, 1987; and Holmes, 1989 used another model for apology strategies which categorized as bellow:

1. An expression of apology: the speaker uses an offer of apology, an expression of regret, and request for forgiveness.

2. An explanation or account: the speaker explains why violation or damage happened.

3. An acknowledgement of responsibility: the apologizer admits to having responsibility for the offense.

4. An offer of repair: speaker may attempt to repair or pay for the damage caused by the offense.

5. Promise for forbearance: the speaker may promise not to repeat the offense in future.

6. Concern for the hearer: the speaker does not necessarily imply any sense of responsibility and carries no risk of damage to speaker's face.

7. Intensification: the speaker's use of adverbial (e.g. terrible, very, extremely, etc) and repetition of IFID (e.g. I'm sorry, please forgive me).

Bergman and Kasper (1993:86) used another category for apology strategies: IFID, downgrading, upgrading or use of adverbials, taking on responsibility or admitting the offense, offer of repair, and verbal redress.

Brown and Attardo (2000: 84) suggest that an apology consists of the following five components:

a. an expression of apology

b. an explanation of the situation

c. an acknowledgment of responsibility happened as a part of his/her apology

d. an offer of repair

e. a promise of non-recurrence

The present study was an attempt:

- To find out (if there is any) different apology strategies in e-mail writing that used by Iranian EFL learners and English native speakers,

- To compare those apology strategies used by those students that send to their professors and those they send to their friends,

- To compare the strategies that used by male and female in strategy use of apology.

\section{RESEARCH QUESTIONS}

1. Is there any difference between Iranian EFL learners and English native speakers in e-mail writing regarding the apology strategies?

2. Is there any relationship between the strategies of apologetic e-mails that students send to their professors and those they send to their friends?

3. Is there any difference between males and females in e-mail writing regarding the apology strategies?

\section{METHODOLOGY}

\section{A. Participants}

Two different groups of participants took part in this study: Iranian EFL learner students and native English speaking students. The first group of participants were 40 (16 males and 24 females) Iranian EFL learner students and the second group were also 40(20 males and 20 females) native English speaking university students. The rationale behind choosing the 40 participants from each situation as a source of data collection was a convenience of sampling. All of the participants were between 24 and 32 in age. The EFL learner participants were solicited from the university students majoring in different academic fields. And also Native English speaking participants were selected through one of friends that knew natives and sending emails to them.

\section{B. Instrument}

This study utilized data from a discourse completion test (DCT). According to Wouk (2006), there are, of course, many advantages disadvantages and in using this type of data. The main advantages of the DCT methodology are that, due to the controlled nature of the study, it is possible to collect and process the data quickly. It is not natural speech, in fact it is not speech at all, and is not produced interactively. However, many studies (beebe \& cummings, 1995; kasper and dahl, 1991; sasaki, 1998) support the use of this instrument for the study of speech acts, which is also the purpose of this study. So the data collection was through a controlled elicitation method based on a modified version of 'Discourse completion Tests' questionnaire used in CCSARP (Blum-Kulka, 1984). The DCT used here (see appendix A) included a brief description of the situations. In other words, the researcher designed a questionnaire consisted of two hypothesized discourse situations, which a university student is likely to encounter in his/her daily language interactions. 
The questionnaire in the study consists of three parts the same as the one used by Bataineh (2005):

1. An introduction of the study and instructions for answering the questions,

2. A section for collecting demographic information about the participants, and

3. 2 scenarios one formal and another informal; each of which involves a situation which requires an apology.

\section{Procedure}

The participants were supposed to answer the questionnaire as if they were writing to their professors (instructors) and as if they were writing to their friends. They were supposed to put themselves in real situations and to assume that in each situation what they would say. The reason for choosing these two particular situations was, because the intention was to select situations that represent how the participants react with what they have done and how they apologize in formal and informal situations. Since the questionnaire had already been piloted and checked for reliability (Bataineh, 2005) the researchers did not conduct a pilot study. Furthermore, it was somehow modified by the researcher. And finally it was judged by some experts in the field to assure its content validity.

\section{Data Analysis}

A discourse-pragmatic analysis was used to analyze the apologetic e-mails collected for the study. The researcher identified the strategies used by the respondents and then classified them based on the model used by Eslami and Eslami (2007); Blum Kulka (1984); Trosborg (1987) and Holmes (1990). Not only was the percentage of the apology strategies used tallied, but also the percentages of those used by the subjects were calculated and compared to discover any potential differences such as gender. First, each e-mail was divided into opening, body and closing. Then, based on the framework employed by Eslami and Eslami (2007), the opening and closing of the emails was analyzed as follows:

I. Openings

A. Salutation: e.g., Hi, Hello

B. (Salutation) + Title: e.g., (dear) + Dr./ Ms./ Mrs./ professor + name of the instructor + (Salutation), Hi/hello (dear) Dr. + name of the instructor

C. Small talk/greeting follow up: e.g., I know how childish is to ask, I know that u are very busy

II. Closings

A. Pre-closing: e.g., wish you a safe journey, have a great new year, thank you

B. Farewell: e.g., regards, sincerely yours

C. Identification of the sender: e.g., Mina, V.P

For the analysis of the body of apologetic emails, the model was used based on the coding scheme developed by Cohen and Olshtain (1981: 113-134) and Olshtain and Cohen (1983: 22-23), as well as on the CCSARP coding manual (Blum-Kulka et al., 1989: 289) as well as Farashaiyan and Amirkhiz, (2011).

Blum-Kulka, et al.'s (1989) coding scheme classifies head acts (i.e., apology strategies) into six different types (Suszczynska, 1999 and Farashaiyan and Amirkhiz, 2011):

(1) Illocutionary Force Indicating Devices (IFIDs)

a. An expression of regret, e.g. I'm sorry

b. An offer of apology, e.g. I apologize

c. A request for forgiveness, e.g. Excuse me/Forgive me

(2) Explanation or Account, e.g. The traffic was terrible.

(3) Taking on responsibility

a. Explicit self-blame, e.g. It is my fault/ my mistake

b. Lack of intent, e.g. I didn't mean it

c. Expression of self-deficiency, e.g. I was confused/ I forgot

d. Expression of Embarrassment, e.g. I feel awful about it

e. Self- dispraise, e.g. I'm such a dimwit!

f. Justify hearer, e.g. You're right to be angry

g. Refusal to acknowledge guilt

Denial of responsibility, e.g. It wasn't my fault

Blame the hearer, e.g. It's your own fault

Pretend to be offended, e.g. I'm the one to be offended

(4) Concern for the hearer, e.g. I hope I didn't upset you

(5) Offer of Repair, e.g. I'll pay for damage

(6) Promise of Forbearance, e.g. It won't happen again

To establish reliability of this coding scheme, intra-coder as well as inter-coder reliability was used. In so doing, after a three-week interval, the content of the e-mails was analyzed and recoded again by the researcher. Also the contents was analyzed and categorized by another coders or raters (the researcher and her colleague) independently using the same analysis table. The researcher used tables (see results section) to clarify the method used to show the different apology strategies employed in each situation and their percentages. Below, the obtained results and the relevant discussion will be reported. 


\section{FINDINGS}

The students' e-mails were analyzed in terms of descriptive statistics. The data were basically nominal and based on frequencies; therefore, percentages were calculated. Each e-mail was analyzed by the researcher with regard to the opening employed in each apologetic e-mail. First, the level of formality and politeness of the openings in e-mails was examined, and then the realization patterns used both by $\mathrm{N}$ and $\mathrm{NN}$ groups and also male and female were investigated. The analysis of the opening of 80 e-mails, in student - professor situation and student - student (friend - friend) situation are tabulated in the following Tables.

Concerning the research question one, the analysis of the data revealed that the participants used all these apologetic strategies more than the others: a) an expression of regret, and b) an offer of apology c) a request for forgiveness d) explanations/accounts e) concern for the hearer f) promise of forbearance. Frequency and percentage of usage have been reported in the tables 3 and 4 . The following tables illustrate the analysis with regard to the first and second research questions.

TABLE 1-

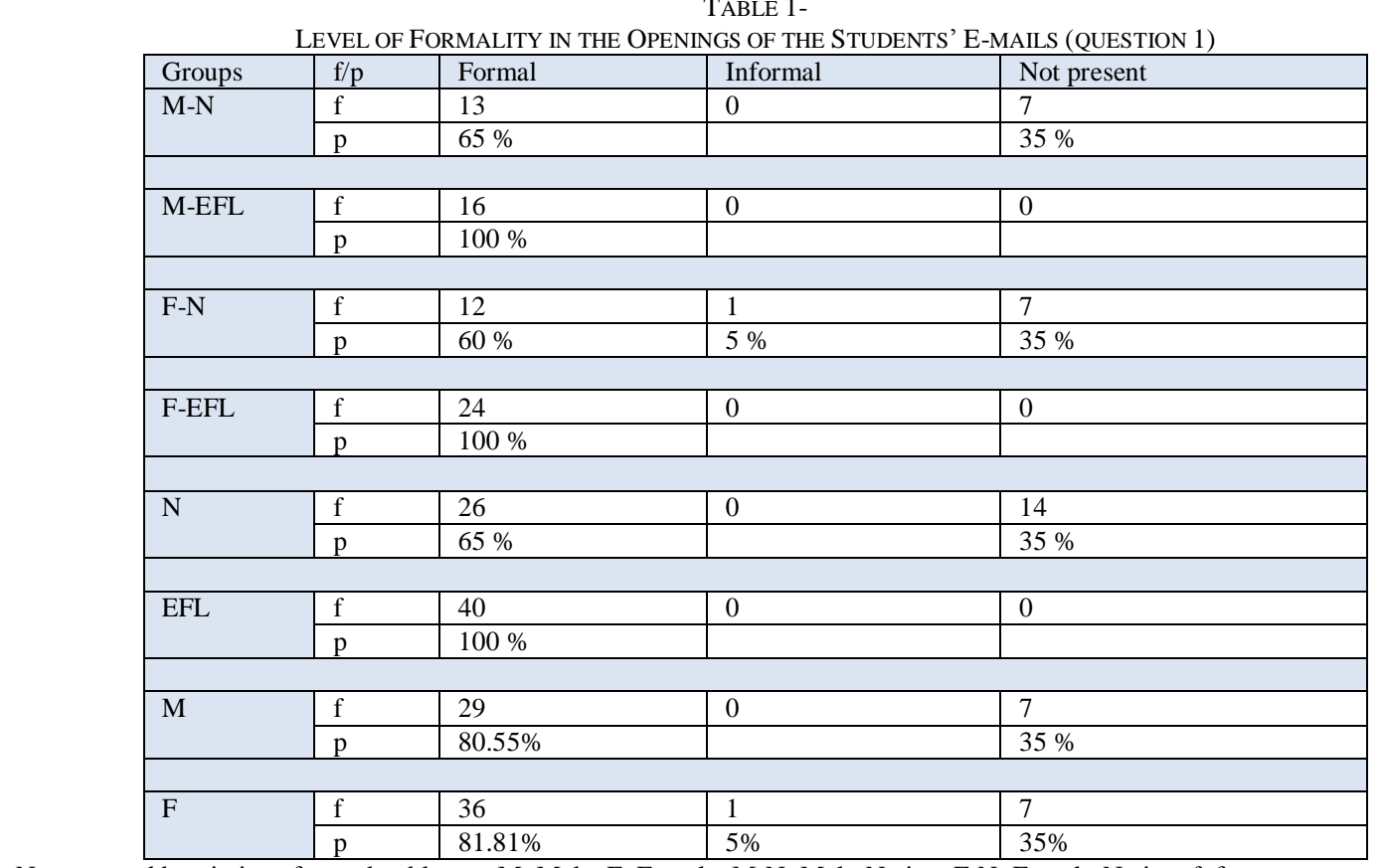

Necessary abbreviations for each table are: M: Male, F: Female, M-N: Male-Native, F-N: Female-Native, f: frequency, p: percentage.

As can be seen in the table, both groups employed some opening realizations in most of the e-mails. For situation one that is a formal situation, all Iranian EFL learner students employed formal openings for addressing their professors $(100 \%)$; the highest percentage of the use of formal address terms was by female EFL learner students followed by male EFL learner students. The opening of the emails was more absent in NESS e-mails compared to EFL learner students that there was no absent. Also all emails that used by males participants had opening.

The use of formal addressing realization patterns was the most common in EFL learners' data (100\%). But related to males and females NESS, males students used $65 \%$ formal address term compared to females students that used $60 \%$. 
TABLE 2-

LEVEL OF FORMALITY IN THE OPENINGS OF THE STUDENTS' E-MAILS (SITUATION 2)

\begin{tabular}{|c|c|c|c|c|}
\hline Groups & $\mathbf{f} / \mathbf{p}$ & Formal & Informal & Not present \\
\hline \multirow{2}{*}{ M-N } & f & 0 & 14 & 6 \\
\hline & p & & $70 \%$ & $30 \%$ \\
\hline \multirow[t]{2}{*}{ M-EFL } & f & 1 & 15 & 1 \\
\hline & $\mathbf{p}$ & $6.25 \%$ & $93.75 \%$ & $6.25 \%$ \\
\hline \multirow[t]{2}{*}{ F-N } & f & 3 & 9 & 8 \\
\hline & $\mathbf{p}$ & $15 \%$ & $45 \%$ & $40 \%$ \\
\hline \multirow[t]{2}{*}{ F-EFL } & f & 0 & 24 & 0 \\
\hline & $\mathbf{p}$ & & $100 \%$ & \\
\hline \multirow[t]{2}{*}{$\mathbf{N}$} & f & 3 & 23 & 14 \\
\hline & p & $15 \%$ & $57.5 \%$ & $35 \%$ \\
\hline \multirow[t]{2}{*}{ EFL } & f & 1 & 39 & 1 \\
\hline & p & $6.25 \%$ & $97.5 \%$ & $2.5 \%$ \\
\hline \multirow[t]{2}{*}{$\bar{M}$} & f & 1 & 29 & 7 \\
\hline & $\mathbf{p}$ & $6.25 \%$ & $80.55 \%$ & $19.44 \%$ \\
\hline \multirow[t]{2}{*}{$\mathbf{F}$} & f & 3 & 33 & 8 \\
\hline & $\mathbf{p}$ & $15 \%$ & $75 \%$ & 40 \\
\hline
\end{tabular}

As illustrated in Table 2, for situation two (an informal situation), Iranian EFL learner students employed informal openings more than native English speaking students; the highest percentage of the use of informal address terms used by female EFL learner students, that followed by male EFL learner students. Less than $98 \%$ of EFL learner students used informal address terms to open their e-mails. The opening was more absent in NESS e-mails compared to EFL learner students.

The use of informal addressing realization patterns was more common in male NN data (93.75\%). All of females NNESS were very informal with their friends (100\%). male NNESS were more informal than males NESS. All females EFL learner students used no opening for interacting with their friends.

The data in table 3 shows the number of actual apology strategies used for situation 1 and the percentage of subjects which used each strategy. 
TABLE 3-

CLASSIFICATION SCHEME FOR THE APOLOGY STRATEGIES (SITUATION1)

\begin{tabular}{|c|c|c|c|c|c|c|c|c|c|c|c|c|}
\hline group & \multicolumn{2}{|c|}{ M-N } & \multicolumn{2}{|c|}{$\mathbf{F}-\mathbf{N}$} & \multicolumn{2}{|c|}{ M-EFL } & \multicolumn{2}{|c|}{ F-EFL } & \multicolumn{2}{|l|}{$\mathbf{N}$} & \multicolumn{2}{|c|}{ EFL } \\
\hline 1.illocutionary force indicating device/IFID & f & $\mathbf{p}$ & $\mathbf{F}$ & $\mathbf{p}$ & f & $\mathbf{p}$ & f & $\mathbf{p}$ & f & $\mathbf{p}$ & f & $\mathbf{p}$ \\
\hline a. Expression of Apology & 10 & $50 \%$ & 8 & $40 \%$ & 4 & $25 \%$ & 9 & $37.5 \%$ & 18 & $45 \%$ & 13 & $32.5 \%$ \\
\hline b.offer of Apology & 7 & $35 \%$ & 7 & $35 \%$ & 5 & $31.25 \%$ & 11 & $45.8 \%$ & 14 & $35 \%$ & 16 & $40 \%$ \\
\hline c. request of forgiveness & 1 & $5 \%$ & 2 & $10 \%$ & 1 & $6.25 \%$ & 3 & $12.5 \%$ & 3 & $7.5 \%$ & 4 & $10 \%$ \\
\hline 2.explanation/account & 18 & $90 \%$ & 18 & $90 \%$ & 14 & $87.5 \%$ & 21 & $87.5 \%$ & 36 & $90 \%$ & 35 & $87.5 \%$ \\
\hline 3.taking on responsibility & 0 & & 0 & & 0 & & 0 & & 0 & & 0 & \\
\hline a. explicit self-blame & 2 & $10 \%$ & 0 & & 0 & & 1 & $4.16 \%$ & 2 & $5 \%$ & 1 & $2.5 \%$ \\
\hline b. lack of intent & 1 & $5 \%$ & 0 & & 0 & & 1 & $4.16 \%$ & 1 & $2.5 \%$ & 2 & $5 \%$ \\
\hline C.expression of self-deficiency & 0 & & 0 & & 0 & & 0 & & 0 & & 0 & \\
\hline D.expression of embarrassment & 3 & $15 \%$ & 0 & & 2 & $12.5 \%$ & 1 & $4.16 \%$ & 3 & $7.5 \%$ & 3 & $7.5 \%$ \\
\hline e. self-dispraise & 0 & & 0 & & & & 0 & & 0 & & 0 & \\
\hline f. justify hearer & 0 & & & & & & 0 & & 0 & & 0 & \\
\hline g. refusal to acknowledge guilt & 0 & & 0 & & 0 & & 0 & & 0 & & 0 & \\
\hline -Denial of responsibility & 0 & & 0 & & 1 & $6.25 \%$ & 0 & & 0 & & 1 & $2.5 \%$ \\
\hline -blame the hearer & 0 & & 0 & & 0 & & 0 & & 0 & & 0 & \\
\hline -pretend to be offended & 0 & & 1 & $5 \%$ & 1 & $6.25 \%$ & 1 & $4.16 \%$ & 1 & $2.5 \%$ & 2 & $5 \%$ \\
\hline 4.concern for the hearer & 7 & $35 \%$ & 8 & $40 \%$ & 9 & $26.25 \%$ & 2 & $8.33 \%$ & 15 & $37.55 \%$ & 11 & $27.5 \%$ \\
\hline 5.offer of repair & 4 & $20 \%$ & 3 & $15 \%$ & 3 & $18.75 \%$ & 4 & $16.66 \%$ & 7 & $17.5 \%$ & 7 & $17.5 \%$ \\
\hline 6.promise of forbearance & 9 & $45 \%$ & 12 & $60 \%$ & 7 & $43.75 \%$ & 16 & $66.66 \%$ & 21 & $52.5 \%$ & 23 & $57.5 \%$ \\
\hline
\end{tabular}

The situation one is a formal situation. In this situation participants tried to be more formal and careful in their relation with their professors. The data collected clearly shows the use of an IFID as the most common strategy for both NSS and NNS. 45\% of NSS used an IFID while 25\% (males) and 37.5\% (females) NNS used this strategy. "I'm sorry" and "I apologize" were the most common choice of an IFID. 1 male NS and 2 females NSS wrote "excuse me" as an apology to their instructors. One male NSS wrote "pardon me" as his response.

None of the participants used these five apology strategies: expression of self-deficiency, self-dispraise, justify hearer, refusal to acknowledgment, and blame the hearer. Only 1 male EFL learner $(6.25 \%)$ used the strategy of denial of responsibility in this situation.

The most common strategies that were used by all of participants were: expression of regret, offer of apology, explanations/accounts, concern for the hearer, offer of repair, and promise of forbearance. 
TABLE 4-

CLASSIFICATION SCHEME FOR THE APOLOGY STRATEGIES USED BY MALES \& FEMALES (QUESTION1)

\begin{tabular}{|c|c|c|c|c|}
\hline \multirow{2}{*}{$\begin{array}{l}\text { group } \\
\begin{array}{l}\text { 1.illocutionary force indicating } \\
\text { device/IFID }\end{array}\end{array}$} & \multicolumn{2}{|c|}{ Male } & \multicolumn{2}{|c|}{ Female } \\
\hline & $f$ & $p$ & $f$ & $P$ \\
\hline a. Expression of regret & 14 & $38.88 \%$ & 17 & $38.63 \%$ \\
\hline b.offer of Apology & 12 & $33.33 \%$ & 18 & $40.90 \%$ \\
\hline c. request of forgiveness & 3 & 8.33 & 5 & 11.36 \\
\hline 2.explanation/account & 32 & $88.88 \%$ & 39 & $88.63 \%$ \\
\hline \multicolumn{5}{|l|}{ 3.taking on responsibility } \\
\hline a. explicit self-blame & 2 & $5.55 \%$ & 1 & $2.27 \%$ \\
\hline b. lack of intent & 1 & $2.77 \%$ & 1 & $2.27 \%$ \\
\hline C.expression of self-deficiency & 0 & & 0 & \\
\hline D.expression of embarrassment & 5 & $13.88 \%$ & 1 & $2.27 \%$ \\
\hline e. self-dispraise & 0 & & 0 & \\
\hline f. justify hearer & 0 & & 0 & \\
\hline g. refusal to acknowledge guilt & 0 & & 0 & \\
\hline -Denial of responsibility & 1 & $2.77 \%$ & 0 & \\
\hline -blame the hearer & 0 & & 0 & \\
\hline -pretend to be offended & 1 & $2.77 \%$ & 2 & $4.54 \%$ \\
\hline 4.concern for the hearer & 16 & $44.44 \%$ & 10 & $22.72 \%$ \\
\hline 5.offer of repair & 7 & $19.44 \%$ & 7 & $15.90 \%$ \\
\hline 6.promise of forbearance & 16 & $44.44 \%$ & 28 & $63.63 \%$ \\
\hline
\end{tabular}

Concerning the research question 3, with regard to the gender differentiation, it can be said: None of the males and females participants used these four apology strategies in their email to their professors: self-dispraise, justify the hearer, refusal to acknowledge guilt, and blame the hearer. 3 males and 5 females choose "excuse me" - 50\% IFIDs used by NSS and $40 \%$ by NNS were "I'm sorry".

Only one male used the strategy of denial of responsibility in his email. Males used more expression of embarrassment strategy (13.88\%) than females that used just $2.27 \%$ from this strategy. The percentage of the females that used the strategies of expression of regret, offer of apology, and promise of forbearance was higher than males'. For females it was $38.63 \%, 40.90 \%, 63.63 \%$, respectively and for males it was $38.88 \%, 33.33 \%$, 44.44\%, respectively. Females used more offer of repair (19.44\%) compared to males that used $15.90 \%$ from this strategy. 
TABLE 5-

CLASSIFICATION SCHEME FOR THE APOLOGY STRATEGIES USED BY MALES \& FEMALES (SITUATION 2)

\begin{tabular}{|c|c|c|c|c|}
\hline Group & \multicolumn{2}{|c|}{ Male } & \multicolumn{2}{|c|}{ Female } \\
\hline $\begin{array}{l}\text { 1.illocutionary force indicating } \\
\text { device/IFID }\end{array}$ & $f$ & $p$ & $\boldsymbol{F}$ & $p$ \\
\hline a. Expression of regret & 28 & $77.77 \%$ & 34 & $77.27 \%$ \\
\hline b.offer of Apology & 4 & $11.11 \%$ & 5 & $11.36 \%$ \\
\hline c. request of forgiveness & 4 & $11.11 \%$ & 7 & $15.90 \%$ \\
\hline 2.explanation/account & 24 & $66.66 \%$ & 19 & $43.18 \%$ \\
\hline \multicolumn{5}{|l|}{ 3.taking on responsibility } \\
\hline a. explicit self-blame & 1 & $2.77 \%$ & 2 & $4.54 \%$ \\
\hline b. lack of intent & 1 & $2.77 \%$ & 1 & $2.27 \%$ \\
\hline C.expression of self-deficiency & 4 & $11.11 \%$ & 9 & $20.45 \%$ \\
\hline D.expression of embarrassment & 1 & $2.77 \%$ & 2 & $4.54 \%$ \\
\hline e. self-dispraise & 0 & & 2 & $4.54 \%$ \\
\hline$f . j u s t i f y$ hearer & 2 & $5.55 \%$ & 0 & \\
\hline g. refusal to acknowledge guilt & 0 & & 0 & \\
\hline -Denial of responsibility & 2 & $5.55 \%$ & 0 & \\
\hline -blame the hearer & 0 & & 0 & \\
\hline -pretend to be offended & 0 & & 0 & \\
\hline 4.concern for the hearer & 6 & $16.66 \%$ & 5 & $11.36 \%$ \\
\hline 5.offer of repair & 14 & $38.88 \%$ & 7 & $15.90 \%$ \\
\hline 6.promise of forbearance & 10 & $27.77 \%$ & 4 & $9.09 \%$ \\
\hline
\end{tabular}

Concerning the research question 3, with regard to the gender differentiation, the analyses show: Three apology strategies were used in this informal situation by neither males nor females. They were: refusal to acknowledge guilt, blame the hearer, and pretend to be offended. Denial of responsibility just used by 2 males and no female used that. The percentage for promise of forbearance that used by females $(27.77 \%)$ were higher than males $(9.09 \%)$. The two most common strategies that were used by males and females were expression of regret and explanations/accounts; $77.77 \%$, $66.66 \%$ for male and $77.27 \%$ and $43.18 \%$ for female participants. 
TABLE 6-

CLASSIFICATION SCHEME FOR THE APOLOGY STRATEGIES (SITUATION 2)

\begin{tabular}{|c|c|c|c|c|c|c|c|c|c|c|c|c|}
\hline \multirow{2}{*}{$\begin{array}{l}\text { group } \\
\text { 1.illocutionary force indicating device/IFID }\end{array}$} & \multicolumn{2}{|c|}{$\mathbf{M - N}$} & \multicolumn{2}{|c|}{$\mathbf{F}-\mathbf{N}$} & \multicolumn{2}{|c|}{ M-EFL } & \multicolumn{2}{|c|}{ F-EFL } & \multicolumn{2}{|l|}{$\mathbf{N}$} & \multicolumn{2}{|c|}{ EFL } \\
\hline & f & $\mathbf{p}$ & f & $\mathbf{p}$ & f & $\mathbf{p}$ & f & $\mathbf{P}$ & f & $\mathbf{p}$ & $\mathbf{f}$ & $\mathbf{p}$ \\
\hline a. Expression of regret & 10 & $50 \%$ & 8 & $40 \%$ & 4 & $25 \%$ & 9 & $37.5 \%$ & 18 & $45 \%$ & 13 & $32.5 \%$ \\
\hline b.offer of Apology & 7 & $35 \%$ & 7 & $35 \%$ & 5 & $31.25 \%$ & 11 & $45.8 \%$ & 14 & $35 \%$ & 18 & $45 \%$ \\
\hline c. request of forgiveness & 1 & $5 \%$ & 2 & $10 \%$ & 2 & $12.5 \%$ & 3 & $12.5 \%$ & 3 & $7.5 \%$ & 5 & $12.5 \%$ \\
\hline 2.explanation/account & 12 & $60 \%$ & 8 & $40 \%$ & 12 & $75 \%$ & 11 & $45.83 \%$ & 8 & $20 \%$ & 23 & $57.5 \%$ \\
\hline \multicolumn{13}{|l|}{ 3.taking on responsibility } \\
\hline a. explicit self-blame & 1 & $5 \%$ & 1 & $5 \%$ & 0 & & 1 & $4.16 \%$ & 2 & $5 \%$ & 1 & $2.5 \%$ \\
\hline b. lack of intent & 1 & $5 \%$ & 0 & & 0 & & 1 & $4.16 \%$ & 0 & & 1 & $2.5 \%$ \\
\hline C.expression of self-deficiency & 1 & $5 \%$ & 7 & $35 \%$ & 3 & $18.7 \%$ & 2 & $8.33 \%$ & 8 & $20 \%$ & 5 & $12.5 \%$ \\
\hline D.expression of embarrassment & 1 & $5 \%$ & 1 & $5 \%$ & 0 & & 1 & $4.16 \%$ & 2 & $5 \%$ & 1 & $2.5 \%$ \\
\hline e. self-dispraise & 0 & & 2 & $10 \%$ & 0 & & 0 & & 2 & $5 \%$ & 0 & \\
\hline f.justify hearer & 1 & $5 \%$ & 0 & & 1 & $6.25 \%$ & 1 & $4.16 \%$ & 1 & $2.5 \%$ & 2 & $5 \%$ \\
\hline g. refusal to acknowledge guilt & 0 & & 0 & & 0 & & 0 & & 0 & & 0 & \\
\hline -Denial of responsibility & 2 & $10 \%$ & 0 & & 0 & & & & 2 & $5 \%$ & 0 & \\
\hline -blame the hearer & 0 & & 0 & & 0 & & 0 & & 0 & & 0 & \\
\hline -pretend to be offended & 0 & & 0 & & 0 & & 0 & & 0 & & 0 & \\
\hline 4.concern for the hearer & 74 & $20 \%$ & 4 & $20 \%$ & 2 & $12.5 \%$ & 1 & $4.16 \%$ & 8 & $20 \%$ & 3 & $7.5 \%$ \\
\hline 5.offer of repair & 13 & $65 \%$ & 3 & $15 \%$ & 1 & $6.25 \%$ & 4 & $16.66 \%$ & 16 & $40 \%$ & 5 & $12.5 \%$ \\
\hline 6.promise of forbearance & 5 & $25 \%$ & 1 & $5 \%$ & 5 & $31.2 .5 \%$ & 3 & $12.5 \%$ & 6 & $15 \%$ & 8 & $20 \%$ \\
\hline
\end{tabular}

In the second situation that is an informal situation, the most common apology strategies that used by native English speaking students and EFL learners were expression of regret and explanations/accounts, $45 \%$ and $20 \%$ used by natives and $32.5 \%$ and $75.5 \%$ EFL learners.

No participants used the refusal to acknowledge guilt, blame the hearer, and pretend to be offended strategies. One male native used explicit self-blame in his email while no male EFL learners used this strategy.EFL learner students used more explains/accounts strategy (57.5\%) than native English speaking students (20\%). No EFL learners used the strategy of self-dispraise while $5 \%$ of native English speaking student used this strategy. 
TABLE 7-

\begin{tabular}{|c|c|c|c|c|}
\hline Groups & $\mathrm{f} / \mathrm{p}$ & Formal & Informal & Not present \\
\hline \multirow[t]{2}{*}{ M-N } & f & 8 & 0 & 12 \\
\hline & $\mathrm{P}$ & $40 \%$ & & $50 \%$ \\
\hline \multirow{2}{*}{ M-EFL } & $\mathrm{f}$ & 10 & 2 & 4 \\
\hline & $\mathrm{p}$ & $62.5 \%$ & $12.5 \%$ & $50 \%$ \\
\hline & & & & \\
\hline \multirow[t]{2}{*}{ F-N } & $\mathrm{f}$ & 4 & 0 & 16 \\
\hline & $\mathrm{p}$ & $20 \%$ & & $75 \%$ \\
\hline \multirow{3}{*}{ F-EFL } & & & & \\
\hline & $\mathrm{f}$ & 19 & 2 & 3 \\
\hline & $\mathrm{p}$ & 79.16 & $8.33 \%$ & $6.25 \%$ \\
\hline \multirow[t]{2}{*}{$\mathrm{N}$} & $\mathrm{f}$ & 12 & 0 & 28 \\
\hline & $\mathrm{p}$ & $30 \%$ & & $70 \%$ \\
\hline \multirow{2}{*}{ EFL } & $f$ & 20 & 0 & 7 \\
\hline & $\mathrm{p}$ & $72.5 \%$ & & $17.5 \%$ \\
\hline \multirow{2}{*}{$\mathrm{M}$} & $\mathrm{f}$ & 18 & 2 & 16 \\
\hline & $\mathrm{p}$ & $50 \%$ & $12.5 \%$ & $44.44 \%$ \\
\hline \multirow{2}{*}{$\mathrm{F}$} & $f$ & 23 & 2 & 18 \\
\hline & $\mathrm{p}$ & $52.27 \%$ & $8.33 \%$ & $40.90 \%$ \\
\hline
\end{tabular}

As it can be seen in Table 7, instructors received formal closings more than informal; females EFL learner students used more formal closing terms compared to the females NSS (about 79\% more). The males EFL learner students were more formal (about 62.5\%), and no informal closing term found in native English speaking students. 75\% females native English speaking students used no term in their closing emails that in comparison to females NNSS were of too much high percentage $(6.25 \%)$.

TABLE 8-

LEVEL OF FORMALITY IN THE CLOSINGS OF THE STUDENTS’ E-MAILS (SITUATION 2)

\begin{tabular}{|c|c|c|c|c|}
\hline Groups & $\mathrm{f} / \mathrm{p}$ & Formal & Informal & Not present \\
\hline \multirow[t]{2}{*}{$\mathrm{M}-\mathrm{N}$} & $\mathrm{f}$ & 3 & 5 & 12 \\
\hline & $\mathrm{p}$ & $15 \%$ & $25 \%$ & $60 \%$ \\
\hline \multirow[t]{2}{*}{ M-EFL } & $\mathrm{f}$ & 1 & 12 & 3 \\
\hline & $\mathrm{P}$ & $6.25 \%$ & $75 \%$ & $18.75 \%$ \\
\hline \multirow[t]{2}{*}{ F-N } & $\mathrm{f}$ & 2 & 7 & 11 \\
\hline & $\mathrm{p}$ & $8.33 \%$ & $35 \%$ & $55 \%$ \\
\hline \multirow[t]{2}{*}{ F-EFL } & $\mathrm{f}$ & 3 & 15 & 6 \\
\hline & $\mathrm{p}$ & $12.5 \%$ & $62.5 \%$ & $25 \%$ \\
\hline & & & & \\
\hline \multirow[t]{2}{*}{$\mathrm{N}$} & $\mathrm{f}$ & 5 & 15 & 23 \\
\hline & $\mathrm{p}$ & $12.5 \%$ & $37.5 \%$ & $65 \%$ \\
\hline \multirow[t]{2}{*}{ EFL } & $\mathrm{f}$ & 4 & 27 & 9 \\
\hline & $\mathrm{p}$ & $10 \%$ & $65.5 \%$ & $22.5 \%$ \\
\hline \multirow[t]{2}{*}{$\mathrm{M}$} & $\mathrm{f}$ & 4 & 17 & 15 \\
\hline & $\mathrm{p}$ & $11.11 \%$ & $47.22 \%$ & $41.66 \%$ \\
\hline \multirow[t]{2}{*}{$\mathrm{F}$} & $\mathrm{f}$ & 5 & 22 & 17 \\
\hline & $\mathrm{p}$ & 11.36 & $50 \%$ & $38.63 \%$ \\
\hline
\end{tabular}

In this situation that is informal, most of the participants have tried to be informal. However there are a number of participants that used formal closing term in this situation. As can be observed in Table 8, EFL learner students employed informal closings more than native English speaking students; the highest percentage of the use of formal closings was by males EFL learner students followed by EFL learners, and female EFL learners. Most of the students either $\mathrm{N}$ or $\mathrm{NN}$ used informal closings to terminate their e-mail interactions with their instructors. The closing was more absent in EFL learner students' e-mails compared to native English speaking students. 
The data depicted in the tables above represent the level of formality of the opening and closing of the emails and various patterns of apology strategies used by both Iranian EFL learner students and native English speaking students in two situations of formal and informal.

The data collected in this study shows that in general, apology strategies between EFL learner students and nonnative speakers of English were not dramatically different. Variation was found, however, in the degree to which the strategies were used between the two groups and also between males and females.

Regarding research question one, the present study aimed to provide a descriptive picture of the typology of apology strategies that Iranian EFL learners and native English speaking students display in dealing with identical apology situations. Exploring these strategies revealed some similarities and differences in Iranians and native English speaking students' tendencies towards utilization of apology strategies. These similarities and differences are indicated very clearly in the tables and it was mentioned in the previous section. From seventeen types of strategies on the DCT, Iranian subjects and native English respondents used twelve and fourteen types of strategies, respectively. In other words, Iranians and native English speaking students used similar types of strategies in many of the situations (thirteen).

One of the points that the data revealed is that while use of an IFID is most common for all the two questions and between two groups. The general trend is that as a situation becomes more formal, participants decided to use other strategies (such as expression of self-deficiency, justify hearer, and explanation/accounts). Table 3 and 4 show also that while there is a general trend for more apologetic strategies when the situation becomes formal, there is not a strict correlation between formality and the number of apology strategies employed.

For the research question 3, according to the figures in Tables 1 and 2, Iranian male and female respondents were different in their use of apology strategies. Although male and female respondents used the various forms of the statement of remorse, it seemed the female respondents had tendency to use this strategy more, options for the various forms of remorse in $25 \%$ of the situations compared to the male respondent's $5 \%$ this is consistent with the claim that females are trained from childhood to apologize more for their mistakes (cf. Brown, \& Attarde, 2000).

The two main strategies used by the females for situation 1(formal), were explanations/accounts and promise of forbearance $(88.63 \%$ and $63.63 \%$, respectively). For situation 2 (informal) the two primary strategies were expression of regret (I'm sorry) and explanation/accounts (77.27\% and $43.18 \%$, respectively). While those used by male respondents for situation 1 were an offer of apology, accounts, concern for the hearer, promise of forbearance (33.33\%, $88.88 \%, 44.44 \%, 44.44 \%$, respectively) and for situation 2, expression of regret, explanation/accounts, offer of repair were the most used strategy $(77.77 \%, 66.66 \%, 38.88 \%$, respectively).

Females respondents tended to use expression of self-deficiency more than their females counterparts, for situation 2 $(20.45 \%, 11.11 \%$, respectively).Males respondents used the strategy of expression of embarrassment in $13.88 \%$ of the first situation, while their female counterparts used this strategy only in $2.27 \%$ of that situation.

According to tables 3 and 6 , the results reveal that the most explicit realization of an apology is the explicit illocutionary force indicating device (IFID). Table 3 and 6 Show that "an expression of an apology (IFID) is the first one in the list of apologies strategies. It is the most direct realization of an apology. As tables demonstrate, the participants used IFIDs in both formal and informal situations at high frequency ranging from $7.5 \%-90 \%$. Regarding the formal situation IFIDs were supplied at high frequency. The respondents used different forms of the expression of remorse. The most common expressions of apology are (IFIDs) e.g. (I am sorry), (pardon), (pardon me) IFID + taking on responsibility. (I am so sorry. It's my fault). IFID + promise of forbearance e.g. (I am sorry for being late. I promise it will be the last time to be late). IFID + interest of the hearer e.g. (I am so sorry, are you OK?) Or IFID + intensifier \& acknowledging responsibility + offer of repair e.g. (I am terribly sorry. It is my fault. Can I help you?)

Both native English speaking and EFL learner students' responses in these two situations display regular use of IFIDs, explanations/accounts, offer of repair, concern for the hearer, and promise of forbearance.

In summary the purpose of this study was to obtain a detailed description of how apologies are realized by Iranian EFL learner students and native English speaking students.

\section{LIMITATIONS AND PEDAGOGICAL IMPLICATIONS}

First of all, the size of the population was relatively small which limits its generalizability. Secondly, the EFL learner participants were solicited from the university students majoring in different academic fields. And also Native English speaking participants were of different cultural and social backgrounds. Therefore, hardly can the findings be generalized beyond this group. Last but not least, the situational factors (Social power, social distance, and gender) were not considered in the analysis of the results in more details.

Moreover, it would have been more desirable if the participants had been interviewed about their apologies. However, it was neither possible for the researcher nor for the participants to have an interview.

The findings of this study may be helpful to the EFL learners who need to know the popular forms of apology as well as the situations in which these forms may be used to communicate effectively and appropriately in their native language. 
Dear Respondent,

I am conducting a research project on pragmatics. I want to analyze the apologetic strategies of native English speakers and compare it with Iranian EFL learner students. I need some English speakers to answer the two following questions. I will appreciate your kindness if you can help me and answer the items.

Thanks,

mohamadi(mohamadi.zeinab65@yahoo.com)

Nationality: age: education: gender:

Please read the two following description of situations and then write what you would SAY in each situation. Please answer as realistically as possible.

1. Imagine that you have postponed the submission of your final project to your professor because of some reason/s. Now you want to send an email to your professor and apologize for that and explain your reason/s. try to persuade your professor!

2. Imagine that you have borrowed the pamphlet of one of your intimate classmates. And just when you were supposed to give it back, you didn't do that because of some reason/s. Now you want to send an email to him/her and make apology and explain the reason/s. Try to make him/her happy!

Thanks

\section{REFERENCES}

[1] Abdullah, M.H. (1998). Electronic discourse: Evolving Conventions in Online Academic Environments. Ertcclearinghouse on Reading, English and Communication, ED 422-593.

[2] Ang-Abey, L. (1991). Transfer Behavior of Hokkien Chinese Speakers in Apologizing. Borneo Research Bulletin 23, 14-35.

[3] Bardovi-Harlig, K. \& Drnyei, Z. (1998). Do Language Learners Recognize Pragmatic Violations? Pragmatic versus Grammatical Awareness in Instructed L2 Learning. TESOL Quarterly, 32 (2): 233-262.

[4] Barnlund, D. \& Yoshioka, M. (1990). Apologies: Japanese and American Styles. International Journal of Intercultural Relations, 14, 193-206.

[5] Bataineh, R. F. (2004). A Cross-Cultural Study of the Speech Act of Apology in American English and Jordanian Arabic. Unpublished $\mathrm{PhD}$ dissertation, Indiana University of Pennsylvania, Indiana PA.

[6] Bataineh Ruba Fahmi and Rula Fahmi Bataineh. (2005). Apology strategies of Jordanian EFL university students. Journal of Pragmatics 38 (11): 1901-1927.

[7] Beebe, L. M., \& Cummings, M. C. (1995). Natural Speech Acts versus Written Questionnaire Data: How Data Collection Method Affects Speech Act Performance. In S. M. Gass \& J. Neu (Eds.). Speech Acts across Cultures: Challenges to Communication in a Second Language (pp. 65-88). New York: Mouton de Gruyter.

[8] Bergman, M. L., Kasper, G., (1993). Perception and Performance in Native and Non-Native Apology. In: Blum-Kulka, Shoshana, Kasper, Gabriele (Eds.), Interlanguage Pragmatics. Oxford University Press, Oxford, pp. 82-107. New York: Oxford University Press.

[9] Biesenbach-Lucas, S. (2005). Communication Topics and Strategies in E-mail Consultation: Comparison between American and International University Students. Language Learning \& Technology, 9(2): 24-46.

[10] Biesenbach-Lucas, S. (2006). Making requests in e-mail: Do Cyber-Consultations Entail Directness? Toward Conventions in a New Medium. In K. Bardovi-Harlig, J. C. Félix-Brasdefer \& A. Omar (Eds.), Pragmatics and language learning (pp. 81-108). Honolulu, HI: Second Language Teaching and Curriculum Center, University of Hawai'i.

[11] Biesenbach-Lucas, S. (2007). Students writing E-mails to Faculty: an Examination of Politeness among Native and Non-native Speakers English. Language Learning \& Technology, 11, 59-81.

[12] Biesenbach-Lucas, S., \& Weasenforth, D. (2000). "Please help me": L1/L2 variations in Solicitations in electronic conferences. Paper presented at the 20th Annual Second Language Research Forum (SLRF), Madison, WI.

[13] Bloch, J. (2002). Student/Teacher Interaction via E-mail: the Social Context of Internet Discourse. Journal of Second Language Writing, 11, 117-134.

[14] Blum-Kulka, S., Juliane H., and Gabriele K. (1989). Cross-Cultural Pragmatics: Requests and Apologies. Norwood New Jersey: Ablex.

[15] Blum-Kulka, Shoshana and Elite Olshtain. (1984). Requests and Apologies: A Cross- Cultural Study of Speech Act Realization Patterns (CCSARP). Applied Linguistics 5: 196-213.

[16] Brown, P., \& Levinson, S. (1979). Politeness: Some Universals in Language Usage. Cambridge: Cambridge University Press.

[17] Brown, P. \& S. C. Levinson. (1987). Politeness. Cambridge: Cambridge University Press.

[18] Brown, S., \& Attardo, S., (2000). Understanding Language Structure, Interaction, and Variation: An Introduction to Applied Linguistics and Sociolinguistics for Nonspecialists. Michigan University Press, Michigan.

[19] Chalak, A., \& Eslami Rasekh, A. (2009). Communicative Purposes in Student- Faculty E-mail Interactions: The Case of Iranian Nonnative Speakers of English. Paper presented at the Annual Research Week, IAUKB, Isfahan, Iran. 
[20] Chen, C-F. E. (2001). Making e-mail requests to professors: Taiwanese vs. American students. Paper presented at the Annual Meeting of the American Association for Applied Linguistics, St-Louis, MO.

[21] Chen, C-F. E. (2006). The Development of E-mail Literacy: From Writing to Peers to Writing to Authority Figures. Language Learning \& Technology, 10(2): 35-55.

[22] Cohen, A. D., \& Olshtain, E. (1985). Comparing apologies across languages. In K. R. Jankowsky (Ed.), Scientific and humanistic dimensions of language. Philadelphia: John Benjamins.

[23] Dadkhah Tehrani, M.D, Rezaei, O. , Dezhara, S., and Kafrani, R.S. (2012). Apology Strategies of Iranian Undergraduate Students. English Language Teaching; Vol. 5, No. 2; P, 93.

[24] Eslami-Rasekh, Z. (2004). Face-Keeping Strategies in Reaction to Complaints: English and Persian. Journal of Asian Pacific Commu nication 14 (1): 181-197.

[25] Eslami-Rasekh, Z. \& Eslami-Rasekh, A. (2007, July). E-mail discourse of native English speaking (NES) and Iranian nonnative English speaking (NNES) TESOL graduate students: Openings and closings. Paper presented at the IELTI 4, Tehran, Iran.

[26] Fraser, B. (1981). On Aapologizing. In Conversational Routine, Florian Coulmas (ed.), 259-273. The Hague: Mouton de Gruyter.

[27] Goffman, E. (1971). Relations in Public: Microstudies of the Public Order. Harmondsworth: Penguin.

[28] Holmes, J. (1989). Sex Differences and Apologies: One Aspect of Communicative Competence. Applied Linguistics 10,194213.

[29] Holmes, J. (1990). Apologies in New Zealand English. Language in Society 19(2): 155-199.

[30] Holmes, J. (1993). New Zealand women are good to talk to: An analysis of politeness strategies in interaction. Journal of Pragmatics, 20(2), 91-116. Retrieved March 30, 2005, from ScienceDirect.

[31] Kasper, G., \& Dahl, M. (1991). Research Methods in Interlanguage Pragmatics (report descriptive). Manoa: Hawaii University, Second Language Teaching and Curriculum Center.

[32] Kim, D. (2001). A descriptive analysis of Korean and English apologies with implications for interlanguage pragmatics. Unpublished PhD dissertation, University of Florida, Gainesville FL.

[33] Kirkley, S.E., Savery, J,. R., \& Garbner - Hagen, M. M. (1998). Electronic Teaching: Extending Classroom Dialogue and Assistance through E-mail Communication. In C.Bonk \& K. King (eds), Electronic Collaborators (pp. 209- 232). Mahwah, NJ: Lawrence Erlbaum.

[34] Kondo, S. (1997). The Development of Pragmatic Competence by Japanese Learners of English: Longitudinal Study on Interlanguage Apologies. Sophia Linguistica, 41, 265-284.

[35] Lee, J. S. (2000). Analysis of Pragmatic Speech Styles among Korean Learners of English: A focus on Complaint-apology Speech Act Sequences. Unpublished PhD dissertation, Stanford University, Stanford CA.

[36] Lee, C. F. K. (2004). Written Requests in E-mails Sent by Adult Chinese Learners of English. Language, Culture and Curriculum, 17, 58-72.

[37] Li, Y. (2000). Linguistic Characteristics of ESL Writing in Task-Based E-mail Activities. System, 28, $229-245$.

[38] Meier, A. J. (1996). Two Cultures Mirrored in Repair Work. Multilingua 15(2): 149-169.

[39] Meier, A. J. (1997). What's the Excuse?: Image Repair in Austrian German. Modern Language Journal 81(2): 197-208.

[40] Nureddeen, Fatima, (2008). Cross cultural pragmatics: Apologies in Sudanese Arabic. Journal of pragmatics 40 (2008) 279$306.197-208$.

[41] Okumura, K. and Li W. (2000). The concept of self and apology strategies in two cultures. Journal of Asian Pacific Communication 10 (1), 124.

[42] Olshtain, E. (1989). Apologies across Languages. In Cross-cultural Pragmatics: Requests and Apologies, Shoshana BlumKulka, Juliane House, and Gabriele Kasper (eds.), 155 73. Norwood, Ne w Jersey: Ablex.

[43] Olshtain, E., \& Cohen, A. D. (1983). Apology: A speech-act set. In N. Wolfson \& E.Judd (Eds.), Sociolinguistics and Language Acquisition (pp. 18-35). Rowley, MA:Newbury House.

[44] Owen, M. (1983). Apologies and Remedial Interchanges. Berlin/New York: Mouton de Gruyter.

[45] Poling, D. J. (1994). E-mail as an Effective Teaching Supplement. Educational Technology, 34 (5): 53-55.

[46] Robinson, J. D. (2004). The Sequential Organization of "Explicit" Apologies in Naturally Occurred English. Research on Language and Social Interaction, 37 (3): 291-330.

[47] Rod, Z. M., \& Eslami-Rasekh, Z. (2005). E-mail discourse of native and non-native TESOL graduate students: openings. Paper presented at the meeting of Pragmatics and Language Learning, Bloomington, IN.

[48] Sasaki, M. (1998). Investigating EFL Students' Production of Speech Acts: a Comparison of Production Questionnaires and Role Plays. Journal of pragmatics, (30)4, 457-484. Retrieved December 2, 2005, from science direct.

[49] Shariati,M \& Chamani, F. ( 2010). Apologies Strategies in Persian. Journal of Pragmatics, 42(6): 1689-1699.

[50] Shetzer, H. (1998). Critical Reflection on the Use of Email in Teaching English as a Second Language. Unpublishes masters' thesis, university of Illinos at Ukbana-Champaign. Retrieved June 14, 1999, from http: //www. Internetsmart.com/ Shetzer 97/.

[51] Suszczynska, M. (1994). A Study in Intercultural Pragmatics: Apology. Studies in Applied Linguistics 1, 11- 22.

[52] Suszczynska, M. (1999). Apologizing in English, Polish and Hungarian: Different Languages, Different Strategies. Journal of Pragmatics 31: 10, 53- 65.

[53] Trosborg, A. (1987). Apology Strategies in Natives/Non-Natives. Journal-of-Pragmatics, 11, 147-167.

[54] Worrel, D.S. (2002). Asynchronous Distance Learning: E-mail Attachments Used as the Medium for Assigned Coursework. Atea journal, 29(2): 4-6.

[55] Wouk, F. (2006). The Language of Apologizing in Lombok, Indonesia. Journal of Pragmatics, 38, 1457-1486.

Zeinab Mohamadi is M.A. graduate of TEFL in the University of Isfahan, Iran. Her research interests are teaching and applied linguistics. 